\title{
EDITORIAL
}

\section{Shedding new light on wood smoke: a risk factor for respiratory health}

\author{
C. Boman*, B. Forsberg" ${ }^{\#}$ and T. Sandström ${ }^{\natural}$
}

$\mathbf{T}$ he burning of wood is probably our oldest source for heating and cooking, and has been used by man for tens of thousands of years. Combustion of biomass, such as wood, animal dung and crop residues, is still used for cooking and heating by a large proportion of the global population, especially in less developed countries. In the industrialised world, and in countries with a cold winter climate, wood and other biomasses are widely used for heat production in residential wood log boilers, stoves and fireplaces. With the recognition of the limitations in amounts and durability of petroleum-based products, as well as an increasing concern regarding the issue of global warming, the interest in wood and other biomasses as alternative, sustainable and $\mathrm{CO}_{2}-$ neutral energy sources for fuel production and heating has emerged.

In the present issue of the European Respiratory Journal, OROzCOLEVI et al. [1] studied wood-smoke exposure and the risk of chronic obstructive pulmonary disease (COPD) in Spain. This contradicts the common assumption that "natural and biological materials" are generally friendly and harmless, as they have been in use since ancient times. Concerning the emissions from domestic wood and charcoal combustion, there is clearly a background of a large number of organic and inorganic components that may be associated with adverse biological events. The potential health effects of by-products, such as volatile organic compounds, polycyclic aromatic hydrocarbons and fine particulate matter (PM), have been of particular concern for these types of pollution sources. Furthermore, it is well known that the emission performance may vary significantly depending on appliance type, fuel properties and operation procedures [2]. Considerable amounts of products of incomplete combustion are often emitted into the air, indoor or ambient, as a result of poorly optimised conditions. Besides condensable organic compounds and soot, different fine particle-forming ash components and metals also constitute the PM in wood smoke [2]. Wood smoke is a complex mixture of a large number of gaseous and particulate air pollution components that can certainly possess a risk factor for human health. This notion that wood-smoke pollutants may have toxic effects has also been supported by recent literature. In a review

\footnotetext{
${ }^{*}$ Energy Technology and Thermal Process Chemistry, and ${ }^{*}$ Occupational and Environmental Medicine, Umeå University, and "Dept of Respiratory Medicine and Allergy, University Hospital, Umeå, Sweden.
}

CORRESPONDENCE: T. Sandström, Dept of Respiratory Medicine and Allergy, University Hospital, SE-901 85 Umeå, Sweden. Fax: 46 90141369. E-mail: Thomas.sandstrom@lung.umu.se by ZELIKOFF et al. [3], which mainly focused on animal studies, it was concluded that inhalation of combustion products from wood can, most probably, significantly exacerbate ongoing disease processes.

With regards to health effects from wood-smoke exposure, for a long time there has been a common knowledge about an increased burden of respiratory symptoms, known under different terms in different regions, e.g. "hut lung". This is mainly reported in less developed countries where wood and other biomasses are burned daily for cooking and, periodically, for heating. Such biomass combustion is often carried out in "huts" or other confined spaces where the concentration of byproducts, such as particles, oxides of nitrogen and hydrocarbons, can be high. Since mainly poor populations are affected, there is inadequate information on both exposures as well as the adverse effects. However, based on a number of epidemiological studies, it has been estimated that indoor air pollution from solid fuels, mainly in developing countries, is responsible for $>1.6$ million premature deaths annually caused, for example, by COPD, tuberculosis, respiratory infections and cancer [4]. It has further been shown that females in these kinds of environments are particularly affected [5, 6], probably as a result of higher exposure to wood-smoke-polluted indoor air. Recently, it has also been suggested that maternal exposure to biomass smoke could cause reduced birth weight [7], meaning that the problem may have another dimension.

Several epidemiological studies have quantified the health effects of wood smoke in outdoor air. A recent review found nine relevant papers that focused on the effects of variations of short-term exposure, such as asthma admissions, respiratory symptoms, daily mortality and lung function [8]. All the included studies reported associations between short-term airpollution levels and one or more adverse health outcomes. PM was the pollutant that showed the most frequent and most robust associations with the addressed health effects. In all studies using particle concentration as pollution indicator, significant positive associations were found. Overall, the relative risks between an increase in ambient PM10 (PM of $\leqslant 10 \mu \mathrm{m})$ and different health outcomes varied between 1.8 and $11.7 \%$. Interestingly, studies from areas where wood smoke was a major source reported, in general, stronger effects of PM10 in comparison with World Health Organization and other state-of-the-art estimations of risk coefficients for PM.

Wood smoke, as with other types of particulate pollution, can cause worsening of asthma symptoms. There are also 
indicative findings from Latin America, India and Sweden that the prevalence and incidence of asthma can be associated with wood-smoke exposure [9-11].

With regards to wood smoke and COPD, there are a few studies from countries such as Mozambique, Bolivia, Mexico, Iran and New Guinea. However, the study by OrOzCO-LEvI et al. [1] demonstrates for the first time that wood smoke may be an underestimated risk factor for COPD in Europe in general, but possibly in Spain in particular. Using case-control methodology, the investigators were able to demonstrate wood or charcoal smoke not only to be associated with COPD after compensating for smoking, but the data also suggested a doseresponse pattern. The strongest association was found after exposure to a combination of pollution from wood and charcoal combustion which more or less tripled the odds ratio from those of the individual components up to 4.5. It is also important to address the fact that the types of combustion units that are still common today in Spain, as well as other European countries, are rather old stoves and fireplaces with simple and inefficient technology.

The recent findings of an association between wood and charcoal smoke exposure with COPD in Spain, together with earlier reported effects of wood-smoke exposure or soot particles (e.g. acute asthma) in Europe and other more developed regions, draws new attention to the toxicological aspects of biomass-smoke components. Presently, this kind of indoor and outdoor air pollution is commonly produced by poor and incomplete combustion in stoves, boilers and other fire places with relatively old technology. A significant potential for the use of new technology and upgraded biomass fuels exists today that will considerably reduce the emissions of unburned by-products, such as hydrocarbons and soot particles. However, a detailed understanding of the chemical and physical properties of biomass combustion aerosols and the specific links to different biological responses is still missing.

Currently, while increasing interest and activities are focused on a more extensive use of wood and other biomasses as an alternative energy source for cooking and heating purposes, as well as production of power and liquid fuels, it is important to advance the biomedical understanding of adverse health effects associated with biomass combustion-related air pollution.

\section{REFERENCES}

1 Orozco-Levi M, Garcia-Aymerich J, Villar J, RamírezSarmiento A, Antó JM, Gea J. Wood smoke exposure and risk for chronic obstructive pulmonary disease. Eur Respir J 2006; 27: 542-546.

2 Boman C. Particulate and gaseous emissions from residential biomass combustion. Umeå University, Umeå, Sweden, 2005.

3 Zelikoff JT, Chen LC, Cohen MD, Schlesinger RB. The toxicology of inhaled woodsmoke. J Toxicol Environ Health B Crit Rev 2002; 5: 269-282.

4 Ezzati M, Hoorn SV, Rodgers A, et al. Estimates of global and regional potential health gains from reducing multiple major risk factors. Lancet 2003; 362: 271-280.

5 Dennis RJ, Maldonado D, Norman S, Baena E, Martinez G. Wood smoke exposure and risk for obstructive airways disease among women. Chest 1996; 109: 115-119.

6 Sandoval J, Salas J, Martinez-Guerra ML, et al. Pulmonary arterial hypertension and cor pulmonale associated with domestic woodsmoke inhalation. Chest 1993; 103: 12-20.

7 Mishra V, Dai X, Smith KR, Mika L. Maternal exposure to biomass smoke and reduced birth weight in Zimbabwe. Ann Epidemiol 2004; 14: 740-747.

8 Boman BC, Forsberg AB, Jarvholm BG. Adverse health effects from ambient air pollution in relation to residential wood combustion in modern society. Scand J Work Environ Health 2003; 29: 251-260.

9 Schei MA, Hessen JO, Smith KR, Bruce N, McCracken J, Lopez V. Childhood asthma and indoor woodsmoke from cooking in Guatemala. J Expo Anal Environ Epidemiol 2004; 14: Suppl. 1, s110-s117.

10 Mishra V. Effect of indoor air pollution from biomass combustion on prevalence of asthma in the elderly. Environ Health Perspect 2003; 111: 71-78.

11 Thorn J, Brisman J, Toren K. Adult-onset asthma is associated with self-reported mold or environmental tobacco smoke exposures in the home. Allergy 2001; 56: 287-292. 